\title{
CORRECTION
}

\section{Correction to: Isatuximab: First Approval}

\section{Sohita Dhillon ${ }^{1}$}

Published online: 23 May 2020

(c) Springer Nature Switzerland AG 2020

\section{Correction to: Drugs}

https://doi.org/10.1007/s40265-020-01311-1

In the table 'Key clinical trials of isatuximab (Sanofi)', in the left-hand column:

The first row, which currently reads 'Isatuximab, bortezomib, lenalidomide, dexamethasone'.

Should read 'Isatuximab, pomalidomide, dexamethasone'.

The third row, which currently reads 'Isatuximab, pomalidomide, dexamethasone'.

Should read 'Isatuximab, bortezomib, lenalidomide, dexamethasone'.

The original article has been corrected.

The original article can be found online at https://doi.org/10.1007/ s40265-020-01311-1.

Sohita Dhillon dru@adis.com

1 Springer Nature, Private Bag 65901, Mairangi Bay, Auckland 0754, New Zealand 